Ethiopian Journal of Environmental Studies \& Management 8(6): 650 - 661, 2015.

ISSN:1998-0507

doi: http://dx.doi.org/10.4314/ejesm.v8i6.4

Submitted: January 18, 2015

Accepted: August 14, 2015

\title{
A STUDY ON THE SERVICE RADII AND ACCESSIBILITY TO HEALTH FACILITIES IN SULEJA, NIGER STATE
}

OWOYELE, G.S., AJOBIEWE, T.0., *IDOWU, 0.0., MUSA, DALIL AND OHADUGHA, C. B. Department of Urban and Regional Planning, Federal University of Technology Minna, Niger

State, Nigeria

\begin{abstract}
Government policies over the years has centered on the provision and delivery of healthcare to all. Spatial distribution of health facilities is subject to a number of social and commercial influences and healthcare needs of the population. The objective of this paper analyzed the service radii and accessibility of health facilities to people in different neighborhoods in the study area. The location of all hospitals and clinics in Suleja were identified and mapped with the use of ARCGIS software. Furthermore 231 questionnaires were administered to both male and female patients in the thirty- seven (37) health facilities identified in the study area. Analytical method such as Lorenz curve was used to show the level of inequality between the population and available health facilities. Hospitals and Clinics showed evidence of clustering in Madalla and Kabula districts, the reason for this could be attributed to the disregard of locational issues and the consequences of adopting a particular spatial pattern of healthcare service delivery. Findings revealed that $34.35 \%$ of the respondents travelled less than $1 \mathrm{~km}$ before accessing the hospitals and clinics of their choice, while only about $11 \%$ of the patients travelled far distances from their places of residence; covering over $4 \mathrm{~km}$ before accessing the health facility of their choice. The research sought to proffer recommendations such as the strict adherence to established standards, ideal for minimum distances to health facilities and the proper consideration of health needs of the population when future provision for health facilities is embarked on.
\end{abstract}

Key Words: Accessibility, Distribution health, Facility, Location, Spatial.

\section{Introduction}

The World Health Organization at the Ottawa charter for Health Promotion in 1986 defines health as a resource for everyday life and not the objective of living. Oloyede (2011) further described good health as a prerequisite for global livability of man as it can be seen as a critical component of societal needs, hence the need for equitable distribution of health facilities as a factor sustaining the population of cities. Accessibility to health facilities for an individual in spatial

*Corresponding author: Idowu, O.O.

Email: olu.idowu@futminna.edu.ng perspective and the physical accessibility of a household member to health care facilities are of considerable importance, but it is however constrained by distance (Aregbeyan, 1992). Owoyele (2014) opined that most of the environmental health problems especially at the urban centre in the developing countries are due to the lack of access to health facilities. Therefore access to health facilities has many dimensions, and geographical accessibility, defined as the extent to which the population finds the distance, travel time 
and means of transport to healthcare services acceptable (World Health Organization, 1978).

The equitable distribution of health facilities is one of the indexes to achieve equal access to health services, however there are barriers to the attainment of this goal and they differ from place to place, with such barriers like: availability, accessibility, affordability, acceptability, and accommodation (Fox et al., 2005)

Following the increase in population, rapid rural-urban migration, and urbanization, and faced with massive problems of ill-health, the dissatisfaction with the state of health facilities in Nigeria has centered on its uneven spatial distribution and limited accessibility to them. A major cause of this trend is as a result of the haphazard location of the available health facilities where a great percentage of the populace has no access to.

\section{Concept of Accessibility in Facility Location}

Accessibility in facility location is fundamental, as the inability to physically reach a healthcare facility effectively nullifies any treatment which may otherwise be available (Sanders, 2006). Similarly, Funnel (1976) observed that the problem of accessibility may be minimized by allocating most services in administrative areas rather than to specific locations. The concept of healthcare accessibility has gained much attention in recent years, and as such recent studies on spatial accessibility by Maldzewski and Jackson (2000) cited that spatial accessibility fails to account for economies of scale and operating efficiency in the provision of facilities. Following the rapid advancement in technology of the $21^{\text {st }}$ century, a well Geographic Information System (GIS) computer program has allowed researchers to address the geographical component to access healthcare via spatial statistics (Sanders, 2006). Similar to this view Mitchell (2005) pointed out that spatial statistics involves the use of maps to incorporate analysis of feature locations and spatial relationships alongside tables of attribute values.

However, the concept of spatial analysis is not only restricted to the use of maps like Mitchell rightly presented; it could also be manipulated by making use of inferential statistics and employing the randomization of null hypothesis. In an urban environment, hospital/clinic accessibility could be influenced by their geographic and social features. Therefore, measuring geographic accessibility to health facilities using GIS allows a juxtaposition of such features (geographic and social) against various outcomes. Shaping health facilities to be different, more equitable and effective in new ways is borne out of the need to develop an object oriented data representation of health services in Nigerian urban centres. The importance of the use of GIS in analyzing health facilities on space cannot be overemphasized as it encompasses the design, development and utilization of webbased tools for the description of health situations, epidemiological analyses and public management. Among the following as clearly presented by Premasudha (2010) are the areas where GIS can be used for spatial analysis of health facilities:

1. Spatial description of health events

2. Public health surveillance

3. Health pattern and situation analysis

4. Accessibility to health service

5. Planning and programming of health services and facilities.

Partson (1980) reported that "health services are required and consumed in order to prevent health problems, to 
identify health problems when they occur, to intervene in natural cause of health problems towards recovery, and to alleviate the disabling effects of health problems." Thus, an assessment on the accessibility of health facilities, optimal location of hospitals/clinics and the relationship between existing locations and health care needs which this study seeks to establish is perceived to be worth investigating. The focus of this study is to examine the service radii and geographical accessibility of health facilities using GIS to build an application that can be used for the modeling process of hospital accessibility in Suleja. And also examine the level of inequality in the distribution of health facilities in the study area. The UN report in 2003 considered housing as the general single expenditure as well the significant source of wealth for the homeowners, owning to the fact of its importance, it is also a potential that could harm the health of the people. Owoyele (2014) concluded that there is relationship between neighborhood quality and diseases prevalence among the residence in Minna, He stated that, neighbourhoods with similar quality also have similar illnesses pattern. Thus clusters of neighbourhoods with high quality coincided with clusters of neighbourhoods with healthy population.
This study focuses at examining the service radii and accessibility to health facilities in Suleja, Niger State.

\section{Study Area}

The study area is Suleja, Niger State, it was formerly Abuja town and traditional emirate, Niger State situated on the Iku River, a minor tributary of the River Niger at the Abuchi Hills and lies at the intersection of several roads. Suleja Local Government was established by the Local Government reform of 1976 from the defunct Abuja native authority. The area lies between latitude $7^{\circ} 31^{\prime} \mathrm{N}$ and longitude $7^{\circ} 58^{\prime} \mathrm{E}$. It shares an immediate boundary with Gurara and Tafa in Niger state and Gwagalada in FCT. Suleja is about $20 \mathrm{~km}$ North of Abuja the Federal Capital of Nigeria and about $100 \mathrm{~km}$ North East of Minna the administrative headquarters of Niger state (Aminu et al., 2003). The Local Government covers a land area of 153.4 Sq.km. According to the 1991 population census, Suleja Local Government had a figure of 151,300 persons, this figure rose to 174,638 persons in 1996 . The 2006 provisional population census results showed that Suleja Local Government Area has an estimated population of 216,578 people with males recording 112,672, females 103,906 and a population density of $1,412 \mathrm{~km}^{2}$ (Niger State Facts and Figures, 2011). 


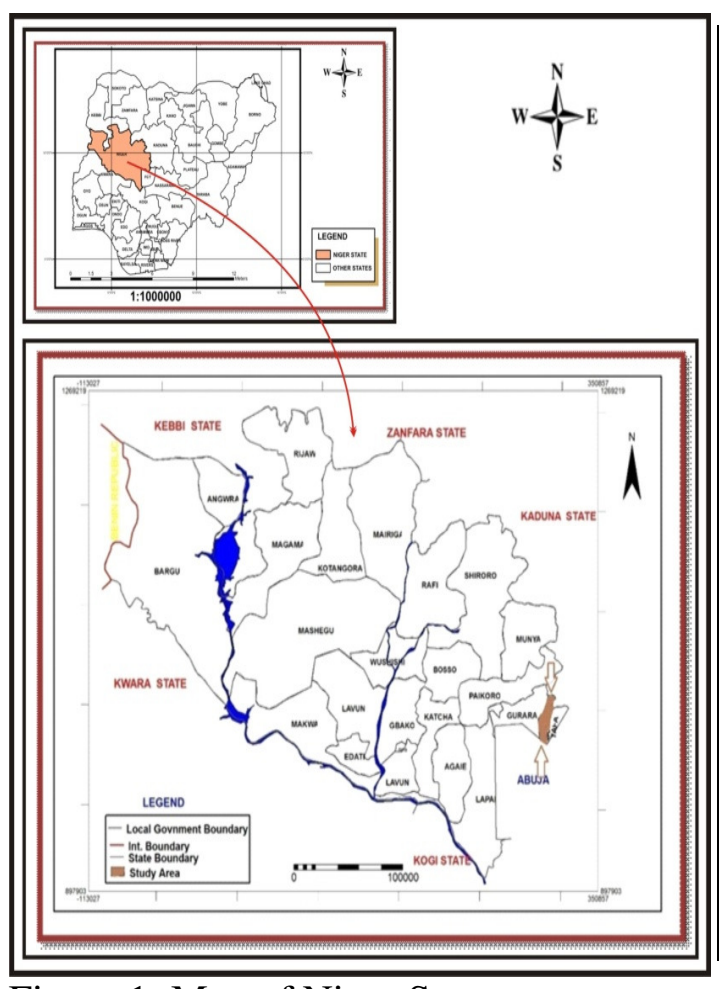

Figure 1: Map of Niger State;

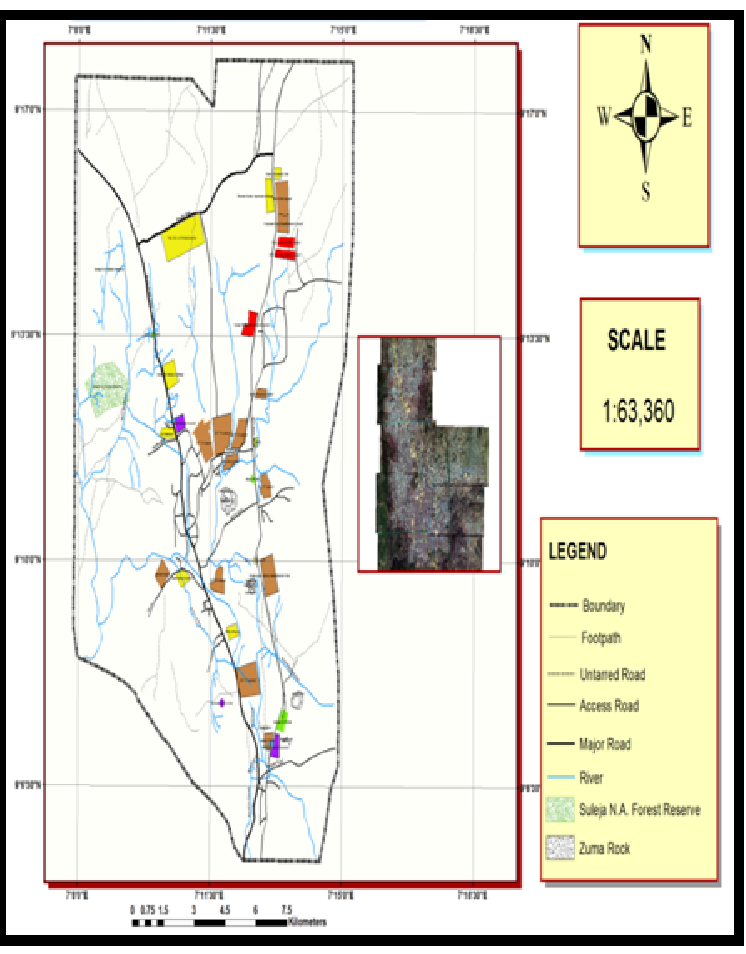

Figure 2: Map of Suleja and Environs

\section{Methodology}

The nature of the study involves primary data collection through comprehensive field survey of all existing health facilities. 244 questionnaires were designed in order to obtain information about patients travel distance, travel time, and means of transportation in accessing health facilities. Stratified random sampling was adopted to first divide the targeted population into two separate, for instance male and female patients. The Sample interval for the study was derived from the daily average population of patients in each of the hospitals and clinics divided by the sample size for the study. Systematic sampling was then eventually used to select the $5^{\text {th }}$ male patient in every five (5) persons and the $1^{\text {st }}$ female patient in every five (5) persons that were interviewed. These questionnaires were distributed on the following basis;

Six (6) questionnaires were administered to every private hospital based on their daily average number of out-patients i.e. every hospital with at least eight (8) out-patients. Twenty percent of the patients out of the 150 average daily of out-patients in General Hospital were selected for questionnaire administration. This resulted in the administration of thirty (30) questionnaires in General Hospital Suleja.

Five (5) questionnaires each were also administered to the twelve (12) clinics in the study area. The yardstick for including and excluding a particular patient are given as follows;

Simple tables, attribute tables, maps, illustrative graphs, proximity analysis, Lorenz curve were employed in the analysis, presentation and interpretation of data.

\section{Inequality and Proximity Analysis}

Lorenz Curve was used to graphically display the level of inequality in the spatial distribution of hospitals and clinics in the study area. Also the stated objective of examining the service radii and 
accessibility of the health facilities to people in different neighborhoods was achieved through GIS using ArcGIS. This was done by selecting one (1) hospital and clinic from each district in the study area. Figures $6 \& 7$ below shows the extent of the area where selected clinics and hospitals serves respectively.

Table 1: Questionnaire Administration Framework

\begin{tabular}{lllll}
\hline S/N & Health Facility & No of Health Facility & $\begin{array}{l}\text { No of Questionnaires } \\
\text { administered }\end{array}$ & Percentage (\%) \\
\hline 1 & Government Hospitals & 1 & 30 & 13.8 \\
2 & Private Hospitals & 24 & 140 & 60.6 \\
3 & Government Clinics & 5 & 25 & 10.8 \\
4 & Private Clinics & 7 & 35 & 15.2 \\
Total & 37 & 231 & 100 \\
\hline
\end{tabular}

The table 1 above shows the framework under which the number of questionnaires administered to every single patient in each of the health facility was carried out.

\section{Data Base Query}

After the creation of a multimedia database which provides detailed information on each of the health facility under studied, series of database query can be performed using ArcGis software
(Ajobiewe, 2014). For this study however, a query on the average daily number of patients who had access to the health facilities understudied.

\section{Results and Discussion}

Distribution of Health Facilities

The study on the distribution of the health facilities covers the nine districts of Suleja as shown in Table 2.

Table 2: Distribution of Health Facilities and Respondents

\begin{tabular}{|c|c|c|c|c|c|}
\hline $\mathrm{S} / \mathrm{N}$ & District & Population & $\begin{array}{l}\text { No of health } \\
\text { facilities }\end{array}$ & No of questionnaires & Percentage \\
\hline 1. & Bagama & 27,009 & 2 & 12 & 5.19 \\
\hline 2. & Magajiya & 26,174 & 1 & 5 & 2.16 \\
\hline 3. & Wambai & 31,947 & 2 & 10 & 4.33 \\
\hline 4. & Kabula & 25,088 & 6 & 35 & 15.15 \\
\hline 5. & Maje \& Kwamba & 29,038 & 2 & 5 & 2.16 \\
\hline 6. & Madalla & 30,643 & 10 & 54 & 23.37 \\
\hline 7. & Hashimi & 24,072 & 7 & 42 & 18.18 \\
\hline 8. & Kurmin Sarki & 27,449 & 4 & 50 & 21.65 \\
\hline 9. & Rafin Sanyi & 32,242 & 3 & 18 & 7.79 \\
\hline Total & & 253,662 & 37 & 231 & 100.00 \\
\hline
\end{tabular}

Table 2 gives an account of the percentage of questionnaires administered in each district of the study area in relation to their respective population, and the number of facility available in each of the ward. 


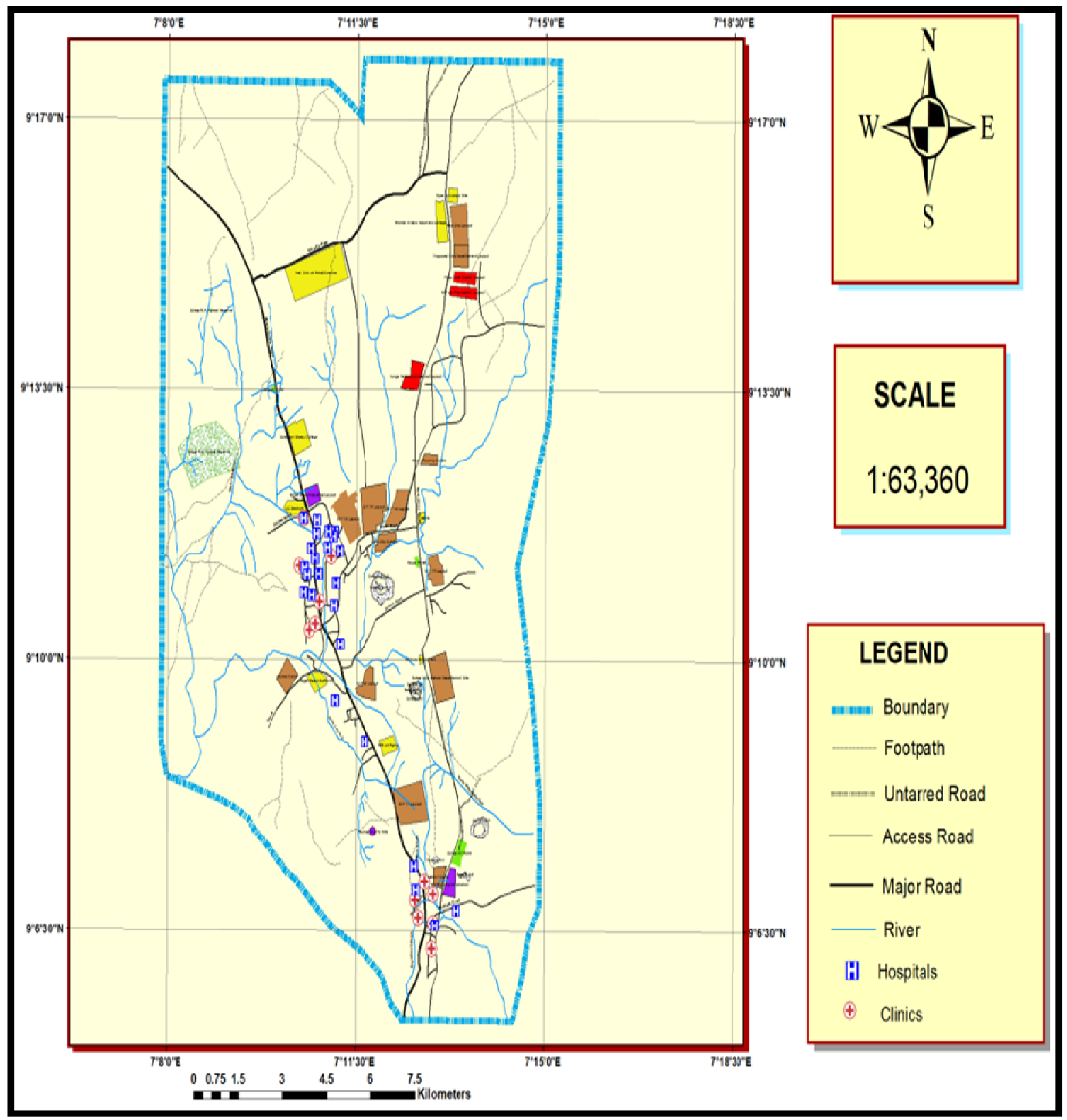

Figure 3: Distribution of health facilities in Suleja

This was performed by the selection of attributes as shown in Figure 4 below. 


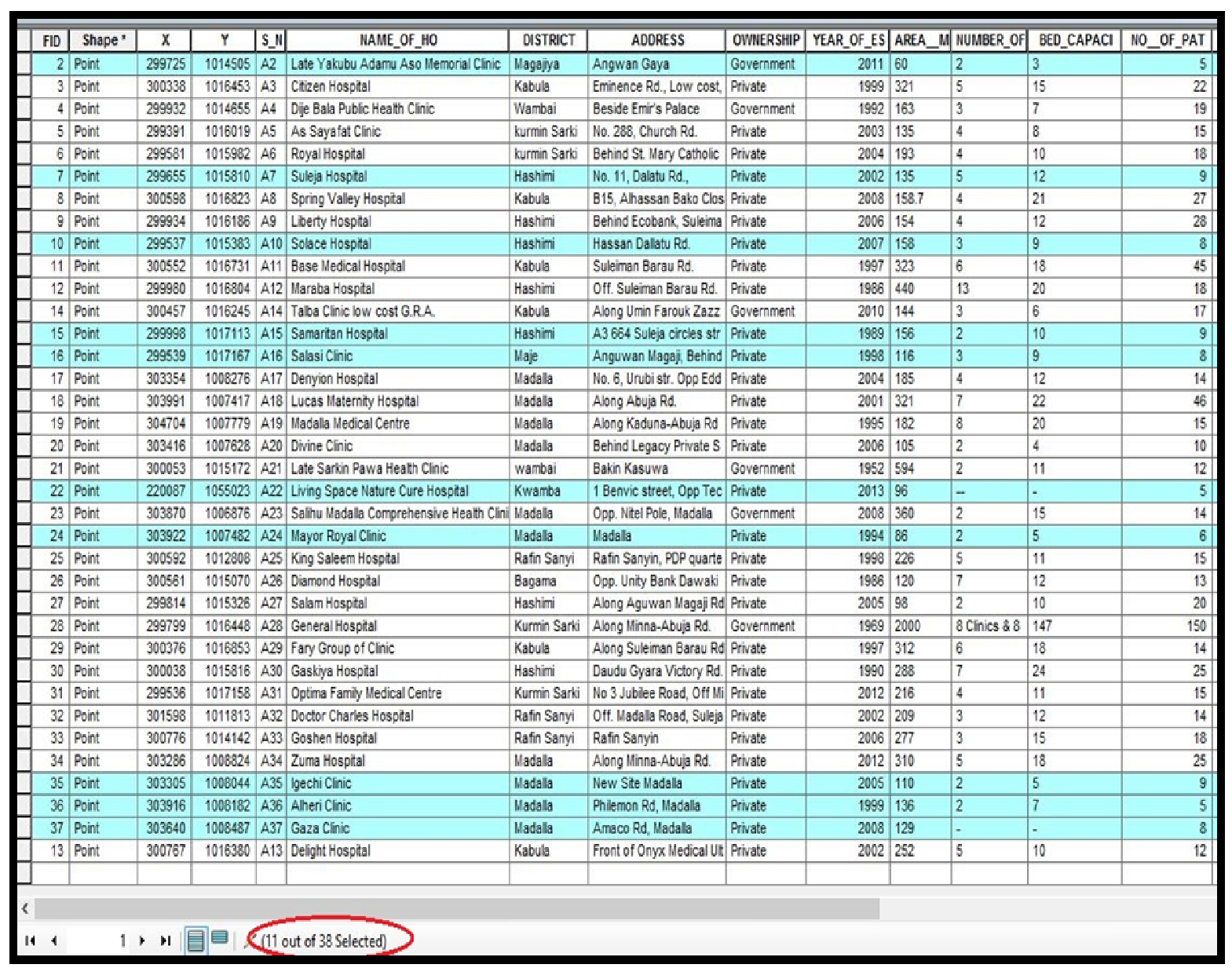

Figure 4: Attribute Table showing average daily patients of Health Facilities in Suleja

Data on the average number of daily out-patients in all the health facilities was collected and coded into the database. Thereafter the computer was asked to search for health facilities with less than 10 daily out-patients and from the result eleven (11) health facilities recorded less than 10 average out-patients daily; among these facilities are Suleja Hospital, Igechi Clinic, Alheri Clinic to mention but a few.

Table 3: Cumulative Percentages of Population and Health Facilities

\begin{tabular}{llllllll}
\hline S/N & District & Population & Pop \% & $\begin{array}{l}\text { Cumulative } \\
\text { Population }\end{array}$ & $\begin{array}{l}\text { Health } \\
\text { Facility }\end{array}$ & Percentage & $\begin{array}{l}\text { Cumulative } \\
\text { Frequency }\end{array}$ \\
\hline 1 & Bagama & 27,009 & 10.64 & 10.64 & 2 & 5.4 & 5.4 \\
2 & Hashimi & 24,072 & 9.49 & 20.13 & 7 & 18.9 & 24.3 \\
3 & Kabula & 25,088 & 9.89 & 30.02 & 6 & 16.2 & 40.5 \\
4 & Kurmin Sarki & 27,449 & 10.82 & 40.84 & 4 & 10.8 & 51.3 \\
5 & Madalla & 30,643 & 12.08 & 52.92 & 10 & 27 & 78.3 \\
6 & Magajiya & 26,174 & 10.32 & 63.24 & 1 & 2.7 & 81 \\
7 & Maje \& Kwamba) & 29,038 & 11.45 & 75.69 & 2 & 5.4 & 86.4 \\
8 & Rafin Sanyi & 32,242 & 12.71 & 87.4 & 3 & 8.1 & 94.5 \\
9 & Wambai & 31,947 & 12.6 & 100 & 2 & 5.4 & 100 \\
& Total & 253,662 & & 100 & 37 & & 100 \\
\hline
\end{tabular}




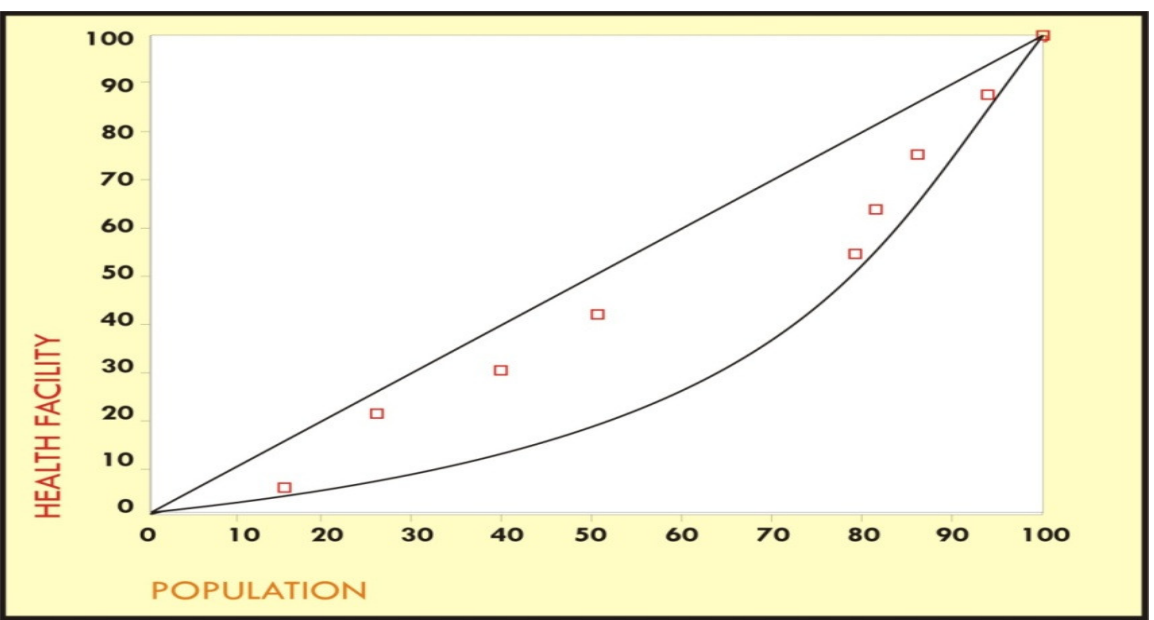

Figure 5: Lorenz Curve of Population and the Number of Health Facilities

The graph presented in Figure 4 reveals that in a situation where the numbers of health facilities provided were to be in consonance with the population, a perfect line i.e. the diagonal would have resulted. Therefore, the deviation between the set of values is shown in the area between the plotted curve and the diagonal line.

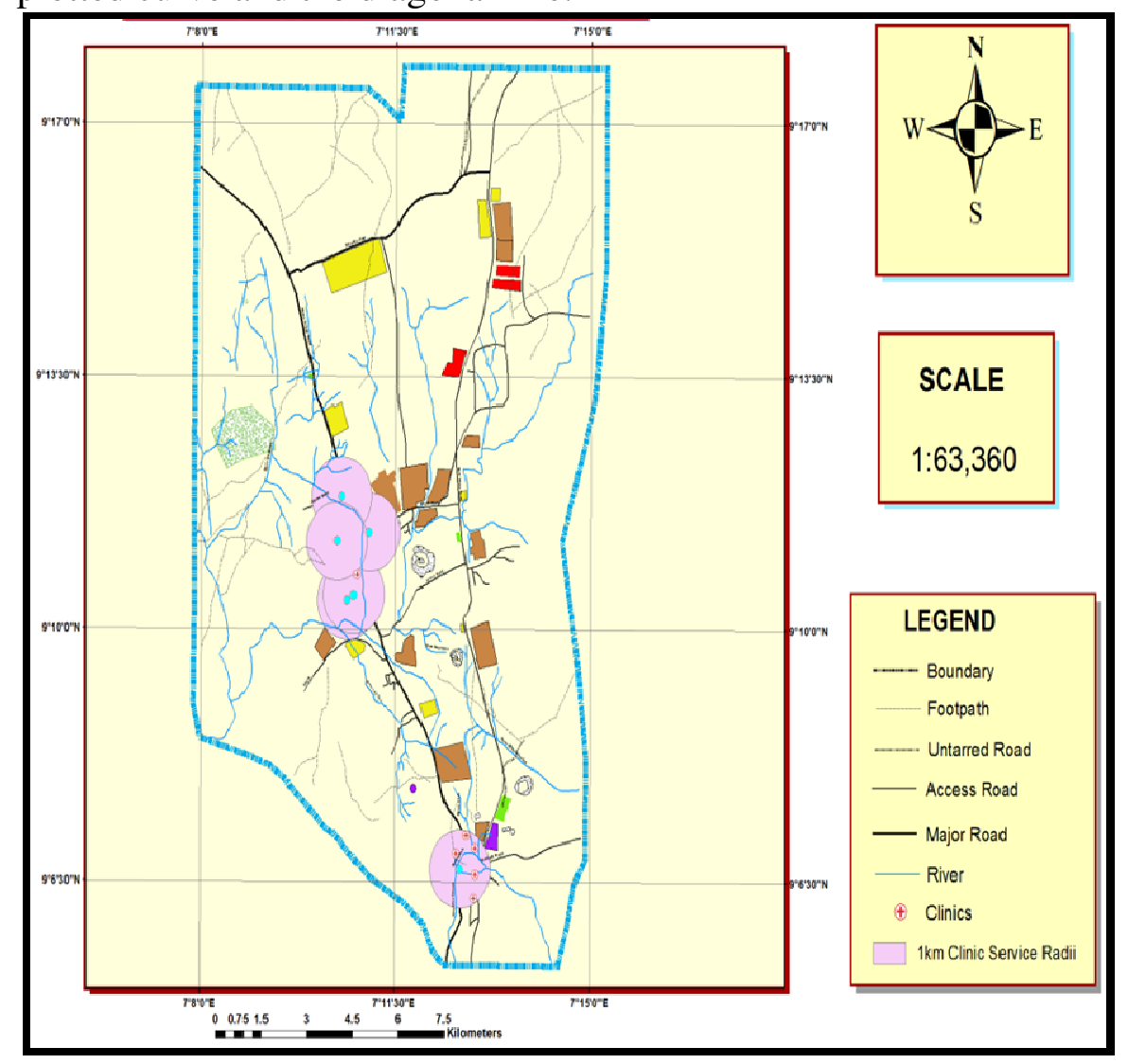

Figure 6: 1km Service Radii of Selected Clinics in Suleja LGA
Service Radii for Health Facilities in Suleja

Figure 6 shows a kilometre service radii served by As-Safayat Clinic, Divine Clinic, Talba Clinic Low-Cost GRA, Late Yakubu Adamu Aso Memorial Clinic, and Salasi Clinic. 


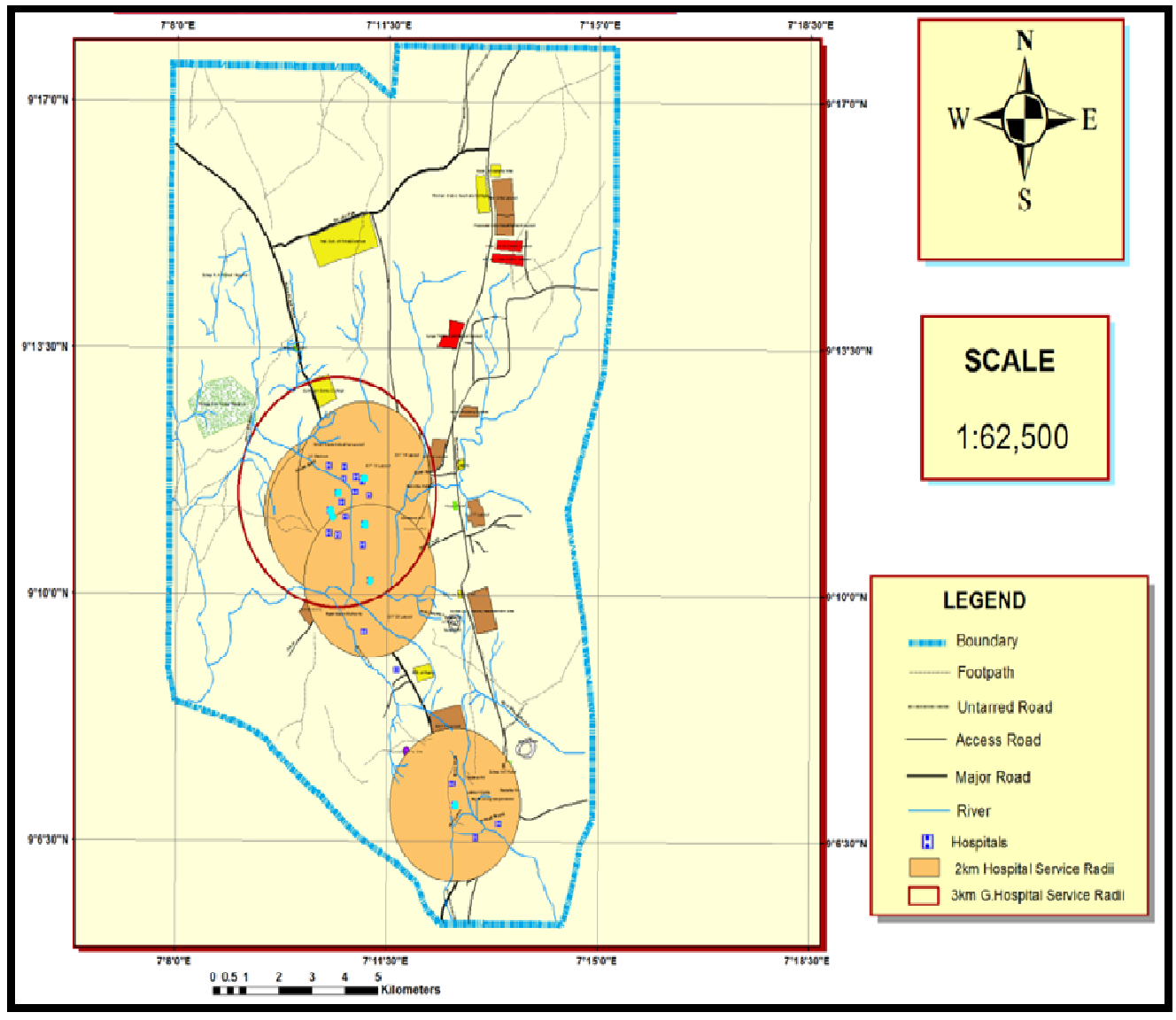

Fig 7: Service Radii of Selected hospitals in Suleja LGA

A $3 \mathrm{~km}$ buffer was created to reveal the service area of the General Hospital Suleja, this can be seen in the red outlined circle from the map in figure 6 above. The General Hospital can be said to serve areas where private hospitals are clustered and located as it overlaps servicing areas of other selected hospitals among which are Suzan Hospital, Royal Hospital, Goshen Hospital, Suleja Hospital to mention but a few.

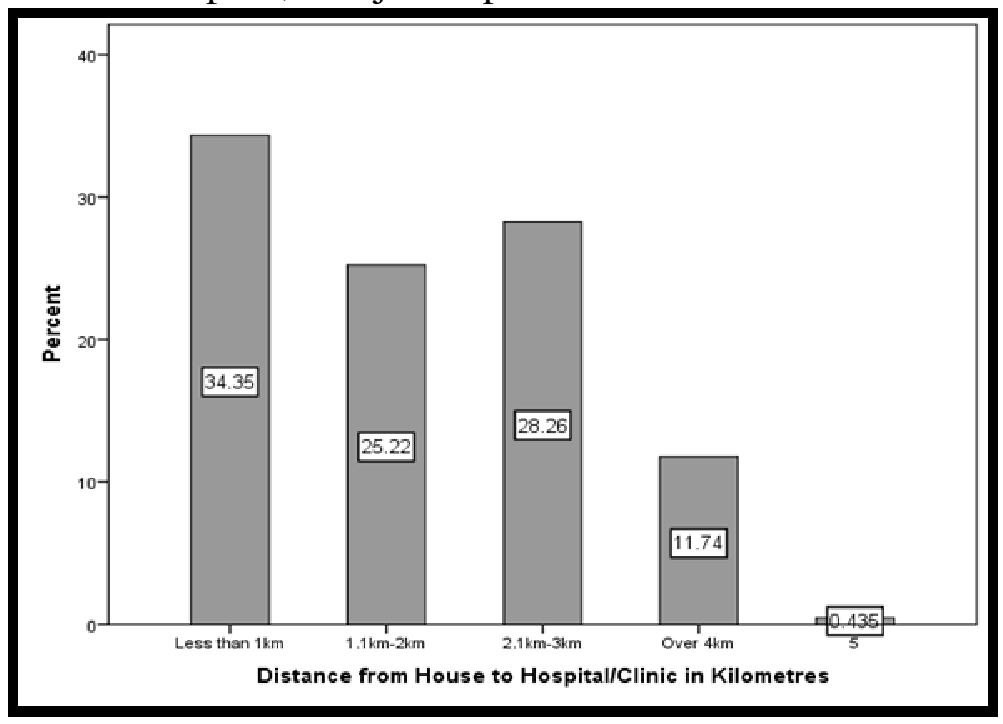

Figure 8: Travel Distance 
Travel distance covered by patients seeking to access healthcare services as confirmed by the survey and shown by Figure $8 ; 34.35 \%$ of the population travelled less than $1 \mathrm{~km}$ before accessing the hospitals and clinics of their choice, while only about $11 \%$ of the patients travelled far distances from their places of residence to places of healthcare facilities. These set of patients covered over $4 \mathrm{~km}$ before accessing the hospitals and clinics of their choice.

Table 4: Travel Costs

\begin{tabular}{llll}
\hline S/N & $\begin{array}{l}\text { Travel } \\
\text { Costs }\end{array}$ & Frequency & $\begin{array}{l}\text { Percentage } \\
(\%)\end{array}$ \\
\hline 1 & Less than & 78 & 33.8 \\
& N100 & & \\
2 & N100-N300 & 83 & 35.9 \\
3 & N300-N500 & 19 & 8.2 \\
4 & N500-N700 & 3 & 1.3 \\
6 & Missing & 48 & 20.8 \\
& Total & 231 & 100.0 \\
\hline
\end{tabular}

From the table 4 above, $33.8 \%$ spent less than $100,35.9 \%$ had to spend between $100-1300$ and $20.8 \%$ of the patients did not spend any money before accessing healthcare facilities; these set of patients travelled by foot to access healthcare services.

\section{Discussion}

The result shows that about 6 (six) of the clinic examine (As-Safayat Clinic, Divine Clinic, Talba Clinic, Low-Cost GRA, Late Yakubu Adamu Aso Memorial Clinic, and Salasi Clinic) are within the radii of $1 \mathrm{~km}$ for the residence of Suleja. The General Hospital serves a wider coverage, even to the distance covered by the private clinics and hospitals in Suleja. Such hospitals include Suzan Hospital, Royal Hospital, Goshen Hospital and Suleja Hospital. The results implies that quite number of people $(34.35 \%)$ travels for health services in a nearby clinic or the hospital, while, few numbers of people
(11\%) travels far distance of more than 4kilometers for the clinic of their choice. These also affect the travel cost of the people from their place of residence to the where the health facility is located as only $9.5 \%$ of the population examined can afford to spend about \#500.00 (Five Hundred Naira) and above to the place of their health facility. However, the majority of the residence in Suleja assessed the clinics and hospital closer to them for any health challenges, but on a special reference to the General Hospital.

\section{Conclusion}

Findings gathered from the research show that there are inequalities in the spatial location/distribution of health facilities (hospitals and clinics) within the study area i.e. more than half of the sampled districts have less than a fair share distribution of hospitals/clinics within the study area, which basically implies that some districts are having inadequate healthcare delivery, while others have excess healthcare facilities clustering around few neighborhoods.

Conclusively, future location of health facilities can be vigorously pursued by using GIS tools. Similarly, government and private owned health establishments must live up to expectation by ensuring better healthcare delivery in all its facets, aspects and ramifications.

\section{Recommendations}

In view of this research, there is need to advise and suggest possible ways to solve the problems identified from the study.

The established standard, ideal for minimum distances for health facility should not be more than $1 \mathrm{~km}$ for health clinic, $2 \mathrm{~km}$ for maternity homes and $3-4 \mathrm{~km}$ for a General hospital. (Onokerhoraye, 1981). A consideration of these set standards will go a long way to resolving 
the present situation where hospitals and clinics are clustered in some districts (Madalla and Kabula districts) and sparsely located in others (Magajiya and Wambai districts).

Apart from established standards, it is expedient that health facilities are located at travel distances of at least 20 minutes from residential areas.

As contained in the vision 3:2020 of Niger state, an implementation of policies contained in the document should be expressly pursued by the state government. This will make it possible to plan for development of districts disadvantaged in terms of healthcare delivery, therefore reducing the discrepancy in the development of the local government area. When locating health facilities, it is necessary to consider methods that take into account spatial hindrances in terms of availability and accessibility

\section{References}

Ajobiewe T.O. (2014). 'Spatial Analysis of Health Facilities in Suleja, Niger State, Nigeria.' Being an Unpublished B.Tech Thesis submitted to the Dept. of Urban and Regional Planning Federal University of Technology, Minna.

Aminu, Z., Yakubu, M., Mohammed, A.A. and Niranjan, K. (2013). 'Impact of Land Use on Soil Quality in Suleja, Niger State.' Indian Journal of Science, 2(2): 1-7.

Aregbeyan, J.B.O (1992). 'Healthcare Service Utilization in Nigeria Rural Communities, A focus on Otuo Community and Environs in Edo state.' NISER Monograph series, Ibadan.

Fox, N.J., Ward, K.J. and O'Rourke, A.J. 2005). 'The 'Expert Patient: Empowerment or Medical Dominance? The Case of Weight loss, Pharmaceutical Drugs and the Internet.' Social Science and Medicine, 60(2): 1299-1309.

Funnel, D.C. (1976). "The Role of Small Service Centers in Regional and Rural Development" with reference to Eastern Africa. pp 73-93.

Maldzewski and Jackson (2000) 'Multi Criteria Spatial Allocation of Education Resources' An overview.' Social Economic Planning Sciences pp 218-237. In http//:www.elsevier.comhacate/ dsw

Mitchell, A. (2005). 'The ESRI guide to GIS analysis': Spatial measurements \& statistics Vol. 2. Redlands, California: ESRI Press.

Niger State Facts and Figures (2011) pp 2230.

Oloyede, M.A. (2011). 'Towards Sustainable Distribution of Health Centers using GIS: A case Study for Nigeria. American Journal of Tropical Medicine \& Public Health, 1(3): 130-136

Onokerhoraye, A.G. (1982). 'Spatial Aspect of Healthcare Problem in Nigeria. 'A Case Study of Kwara State. The quarterly Journal of Administration, 12: 241-255.

Owoyele G.S. (2014). Assessment of the Relationship between Neighbourhood Quality and Human Health in Minna, Niger State. An unpublished PhD Thesis submitted to the Dept. of Urban and Regional Planning Federal University of Technology, Minna.

Partson, G. (1980), Planners Politics and Health Services, New York Institute of Medicine pp88.

Premasudha, B.G (2010). 'Visualization and Spatial Analysis of Healthcare Services of Tumkur City. An Unpublished $\mathrm{PhD}$ Thesis submitted to Computer Applications Dept. Dr 
M.G.R Educational and Research Institute University)

Sanders, L.J. (2006). 'A Spatial Analysis of the Geographic Distribution of Musculoskeletal and General Practice Healthcare Clinics in Auckland, New Zealand.' An Unpublished Master of osteopathy thesis submitted to Unitec Institute of Technology, New Zealand.
UN-Habitat (2003). The Challenges of Slum: Global Report on Human Settlements. Nairobi: UN-Habitat

World Health Organization (1978) 'Primary Health care. Report of the International Conference at Alma Alta, World Health Organization, Geneva, Switzerland. 